\title{
Services for adults with learning disabilities and mental health needs
}

\author{
Shaun Gravestock and Nick Bouras
}

\begin{abstract}
A postal questionnaire assessing key professionals' and managers' viows about local services achloved an overall $72 \%$ response rate. The results demonstrated concems about the range, quanttly and quallty of mental heatth and social care provision for adults with lecoming discablitiles and mental health needs in all 15 districts. Only elght (14\%) respondents provided specilic local service utilisation data, and confusions about care co-ordination responslbilities were evident. Improving future service provision should involve utilling needs ascosements and quallty assurance data to better Inform multi-agency commissioning and purchasing strategles.
\end{abstract}

In line with community care policies (Department of Health, 1989), adults with learning disabilities (LD) are being resettled from long-stay hospitals and supported to remain living in the community. Specialist LD services are increasingly expected to liaise with primary care, generic physical and mental health services, local authorities, and private and voluntary agencies to meet the health and social care needs of adults with LD (Department of Health, 1992).

There is growing awareness of the complex health care needs of people with LD arising from epilepsy, sensory impairments and challenging behaviours (Mansell, 1993). However, the mental health needs (MHN) of adults with LD which arise from diagnosed psychiatric disorders are less often addressed beyond specialist psychiatry of LD services. Yet local research confirmed that over $40 \%$ of adults with $\mathrm{LD}$ referred to specialist $\mathrm{LD}$ services have MHN (Bouras \& Drummond, 1992).

\section{The study}

The South East Thames Regional Health Authority (SETRHA) area comprises 15 London, Kent and Sussex health districts whose total populations range from 160,000 to 330,000 people with a mean district population of 240,000 people. The SETRHA resettlement programme is almost completed with less than 200 adults remaining in five mental handicap hospital units (SETRHA, 1993). This study aimed to focus attention on service provision for adults (aged 19 to 65 years) with LD and MHN by surveying the views of key clinicians and managers about relevant local mental health and social care services in mid-1993.

A semi-structured questionnaire (Q1) was developed to gather mainly descriptive data and some quantitative service utilisation and planning data. The $\mathbf{Q 1}$ was sent to all consultant psychiatrists, senior psychologists, senior nurses and managers in the 15 health authority LD services and to the 16 corresponding local authority LD service managers.

\section{Findings}

The 5581 s returned represented an overall $72 \%$ response rate with at least three responses from 14 out of 15 districts. Using $\chi^{2}$ tests, no statistically significant differences were found between data from different professional and managerial groups nor between grouped data from London, Kent and Sussex districts. Thus, selected data are summarised below for all 55 respondents.

Thirty-six (65\%) respondents were aware of local care registers and $28(51 \%)$ supplied quantitative data on adults using various $\mathrm{LD}$ services. While $29(53 \%)$ reported the operation of care management systems for adults with LD, only $8(14 \%)$ could provide data on the number of adults with LD and MHN using or requiring local services. 
Table 1. Avallabillty, accessibility and adequacy

\begin{tabular}{|c|c|c|c|}
\hline QI I neme & $\operatorname{cosd}(x)$ & Poor (x) & $x^{2}$ \\
\hline $\begin{array}{l}\text { Availabillty of: } \\
\text { LD services } \\
\text { Generic mental health services }\end{array}$ & $\begin{array}{l}31(56) \\
26(47)\end{array}$ & $\begin{array}{l}24(44) \\
27(49)\end{array}$ & $\begin{array}{l}0.59 \\
\text { NS }\end{array}$ \\
\hline $\begin{array}{l}\text { Accessibility of: } \\
\text { LD services } \\
\text { Generic mental health services }\end{array}$ & $\begin{array}{l}33(60) \\
17(31)\end{array}$ & $\begin{array}{l}21(38) \\
38(69)\end{array}$ & $\begin{array}{l}9.94 \\
P<0.01\end{array}$ \\
\hline $\begin{array}{l}\text { Adequacy of: } \\
\text { Psychiatry of LD clinics } \\
\text { Community LD teams } \\
\text { Staffed homes } \\
\text { Respite care services } \\
\text { Supported lodgings } \\
\text { LD hospital units } \\
\text { Generic psychiatric wards } \\
\text { Specialist/generic community mental health teams } \\
\text { Daycare services } \\
\text { Secure units }\end{array}$ & $\begin{array}{c}38(69) \\
35(64) \\
31(56) \\
19(35) \\
18(33) \\
16(29) \\
15(27) \\
15(27) \\
14(25) \\
5(9)\end{array}$ & $\begin{array}{r}7(13) \\
15(27) \\
17(31) \\
29(53) \\
22(40) \\
9(16) \\
28(51) \\
25(45) \\
37(67) \\
17(31)\end{array}$ & \\
\hline
\end{tabular}

Comparing data supplied from different districts indicated a range of local estimates of adults with LD (487-1087) and a wider range of local estimates of adults with $L D$ and MHN (24-300). The range of local estimates were only partially explained by varying total district populations.

Respondents reported providing services for adults with $\mathrm{LD}$ and MHN within a mixed economy of care. Table 1 shows their diverse views about whether the general availability (volume) accessibility and adequacy (volume and quality) of local services for adults with LD and $\mathrm{MHN}$ were good or poor. Missing data are accounted for by respondents without clearcut views, often due to limited or no experience of the given service type locally.

More respondents (37;67\%) described most local clinical provision for adults with LD and MHN as part of specialist LD services rather than integrated with generic mental health services $(15 ; 27 \%)$. Thirty-one(56\%) said most adults with LD and MHN with non-urgent clinical or social needs were assessed within four weeks of referral, while $29(53 \%)$ reported that the local services also responded to crises. The range of respondents' views about which services should be responsible for care coordination for adults with LD and MHN were: $21(38 \%)$ favoured multi-agency care planning; $18(33 \%)$ wanted the LD health services to remain responsible; $10(18 \%)$ were keen on flexble arrangements depending on an individual's level of $\mathrm{LD}$; four(7\%) wanted the generic mental health services but only two (4\%) wanted local authorities to become responsible.

\section{Comment}

Given the SETRHA's advanced resettlement programmes, these results should interest the purchasers and providers of LD services in other regions. The response rate reflected continuing local and national multi-agency interest in planning comprehensive services for adults with LD. The data highlighted specific concerns shared by most local multidisciplinary LD teams and managers in the SETRHA area about the inadequate range, varying quantity and quality of mental health and social care provision, particularly for adults with mild LD and MHN.

LD services were viewed as significantly more accessible than generic mental health services, but the availability and accessibility of both services for adults with LD and MHN could be improved. Employing more clinically trained staff and experienced managers would support adults with $L D$ and MHN receiving services in a wider range of care settings. Some adequate out-patient, community LD team and staffed residential services have been developed in most districts. However, an adequate volume of high quality specialist daycare and respite places, assessment, treatment and secure hospital beds are still 
needed to provide local 'back-up' clinical support for adults with LD and MHN using community LD services (Royal College of Psychiatrists, 1992).

Most respondents acknowledged that the additional clinical service and staff resources needed to support community care developments had not been agreed between local service planning data and the diverse views of respondents about responsibility for care coordination suggest continuing confusions about appropriate mental health and social care provision for adults with $L D$ and MHN in several districts. The varying difficulties using local generic mental health services emphasise the essential clinical and advisory roles of existing specialist psychiatry of LD services. Such roles include supervision of psychiatric treatment and rehabilitative care, input to community LD teams, monitoring adults with LD and chronic MHN and crisis intervention support.

These findings broadly confirm similar concerns raised by a survey in the West Midlands Region (Roy \& Cumella, 1993). They showed greater use of mental handicap hospital assessment and treatment beds for adults with LD and MHN rather than mainly admitting to generic psychiatric wards as in the SETRHA districts. Both surveys encouraged psychiatrists' involvement in developing co-ordinated multi-agency local purchasing strategles.

Central government has attempted to clarify the continuing responsibilities of local LD health services and other providers towards adults with $\mathrm{LD}$ and additional MHN, challenging behaviour, physical nursing needs and those who offend (Department of Health, 1992; Reed, 1992; Mansell, 1993). These data, a related report (SETRHA, 1993) and our current national survey also hope to encourage better informed future commissioning of local multidisciplinary and multi-agency hospital and community service provision, as advised by the Royal College of Psychiatrists (1992).

Local individual and population need assessments and care management systems must include specific data on adults with LD and MHN. Otherwise their health and social care needs will not be adequately met within evolving complex economies of community care. Integrated quality assurance systems (Gravestock, 1994) should also provide local LD, mental health and local authority service providers with data to stimulate improvements in the health and social gains of adults with $L D$ and MHN using finite hospital and community resources.

\section{Acknowiedgements}

We thank Mr Jack Kellett at SETRHA and other colleagues in the region for their advice and support.

\section{References}

BOURAS, N. \& DRUMMOND, C. (1992) Behaviour and psychiatric disorders of people with mental handicaps Iiving in the community. Joumal of Intellectual Disability Research, 38, 349-357.

DEPARTMENT OF HEALTH (1989) Caring for People: community care in the next decade and beyond. London: HMSO.

- (1992) Health Services for People with Learning Disabilities. London: HMSO.

GRAVESTOCK, S. (1994) Quality assurance for adults with mental retardation and mental health needs. In Mental Health in Mental Retardation (ed. N. Bouras), pp 319 327. Cambridge: Cambridge Untversity Press.

Manselu, J. L. (1993) Services for People with Learning Disabilities and Challenging Behaviour or Mental Health Needs. London: HMSO.

REED, J. (1992) Review of Health and Social Services for Mentally Disordered Offenders and Others Requiring Similar Services. London: HMSO.

RoY, A. \& CumeuA. S. (1993) Developing local services for people with a learning disability and a psychiatric disorder. Psychiatric Bulletin. 17, 215-217.

ROYAL COULGE OF PSYCHIATRISTS (1992) Mental Health of the Nation. London: Royal College of Psychiatrists.

SETRHA (1993) The Mental Health Needs of People with Learning Disabilities: report of a working group set up by SETRHA. Kent: SETRHA Institute of Public Health.

*Shaun M. Gravestock, Locum Consultant and Nick Bouras, Consultant and Senior Lecturer, Division of Psychiatry. UMDS Guy's Hospital, London SE1 9RT

*Correspondence 